\title{
Dental Students' Attitudes Toward the Design of a Computer-Based Treatment Planning Tool
}

\author{
Lea Foster, B.D.Sc.; Kathy Knox, B.Psych. (Hons); Andrea Rung, B.D.Sc.; \\ Nikos Mattheos, D.D.S., M.A.Sc. (Perio), Ph.D.
}

Abstract: The purpose of this study was to identify and evaluate the attitudes of a cohort of fourth- and fifth-year dental students $(\mathrm{n}=53)$ at Griffith University in Australia to a proposed computer-based Case Study and Treatment Planning (CSTP) tool. The tool would allow students to work through the process of comprehensive, multidisciplinary treatment planning for patients in a structured and logical manner. A questionnaire was designed to investigate the students' perceived needs, attitudes, and factors deemed to be important in the design of such a tool. Students responded on a seven-point Likert scale ranging from 1 (strongly disagree) to 7 (strongly agree). The survey was supplemented by two focus groups, one of fourth-year and one of fifth-year students. The survey results indicated strong agreement that there is a need for such a tool (fourth-year mean=6.24; fifth-year mean=5.75) and the likelihood that it would be used after hours and for extra treatment planning practice (fourth-year mean=5.82; fifth-year mean=5.45). The themes that emerged from the focus groups revealed students' agreement that a CSTP tool would be beneficial both for training and for faculty assessment of students' treatment planning skills. The type of concerns raised included whether a rigid treatment planning template might hamper the flexibility needed to deal with complex patient cases. Additionally, there was some concern that students' personal interaction with tutors would be reduced if this mode of computer-based treatment planning were to be used exclusively. In conclusion, the overall attitude of dental students was positive towards a CSTP tool. This study's findings provide guidance as to how such software could be developed and which features to include.

Dr. Foster is Lecturer, Comprehensive Care Clinic, Griffith University, Queensland, Australia; Ms. Knox is Research Associate, School of Psychology, Griffith University, Queensland, Australia; Dr. Rung is Lecturer, Comprehensive Care Clinic, Griffith University, Queensland, Australia; and Dr. Mattheos is Associate Professor, Griffith University, Queensland, Australia. Direct correspondence and requests for reprints to Dr. Nikos Mattheos, Griffith University, 16-30 High Street, Gold Coast, Queensland 4215, Australia; nikos@mattheos.net.

Keywords: computer-assisted instruction, computers in dentistry, clinical education, teaching assessment, dental students, treatment planning, blended learning

Submitted for publication 1/6/11; accepted 3/23/11

$\mathrm{C}$ linical education for students at Griffith University School of Dentistry and Oral Health in Queensland, Australia, is based on the principles of holistic and comprehensive care. From an early stage in their dental education, students are required to attend treatment planning sessions in groups and undertake responsibility for comprehensive care of patients, while later in their studies senior students become responsible for chairing these sessions. The planning of comprehensive dental treatment, especially with complicated multidisciplinary cases, poses challenges even to experienced practitioners. Students, particularly early in their dental education, are faced with a demanding educational challenge: they must not only acquire a great deal of factual knowledge, but must learn synthetic and analytic problem-solving skills to apply this knowledge to real-life, complex patient management. The development of the relevant skills is a slow process that requires considerable guidance from tutors and more experienced peers and clearly benefits from continuous practice. Self-directed computer-based training has been shown to be a very useful tool in such circumstances..$^{1-4}$

The Griffith University School of Dentistry and Oral Health $(\mathrm{DOH})$ is willing to invest in the development of a computer-based Case Study and Treatment Planning (CSTP) software that will allow students to work through the process of comprehensive, multidisciplinary treatment planning for patients in a structured and logical manner. Crespo et al. ${ }^{5}$ examined the reasoning skills of expert dentists and found them to be qualitatively different from those of beginner and competent clinicians. They have proposed that such skills could be taught, concluding that students' clinical experience would be enhanced by exposing them to as wide a variety of cases as possible. Crespo et al. suggested that case-based scenarios could be utilized to inculcate an understanding of the processes of clinical decision making. Since clinical time in 
predoctoral dental curricula is constrained, students can be exposed to only a limited sample of the entire array of clinical conditions. Case-based teaching may provide a means to ease these constraints. ${ }^{6}$

The proposed CSTP software could be a significant instructional tool for the development and practice of cognitive skills relevant to treatment planning through a library of structured patient cases of increasing complexity. Furthermore, connected with the patient management system of the clinic, the software could also be used by students for organizing and planning their own clinical cases. Finally, such software could become a valuable assessment tool.

Research has shown that users' acceptance is a major factor for the success of every computerbased educational intervention..$^{7-10}$ Flexible-learning instructional material has the potential to meet the needs of the individual and a cohort. ${ }^{11}$ Prior to the design of courseware, a first investigation is necessary to identify factors of importance and usability from the user's point of view. Such research is often described as "Reaction" level research, ${ }^{12}$ investigating users' attitudes, acceptance, and reactions. Sweeney ${ }^{13}$ conducted more than thirty-five focus groups with college students categorized as Millennials (born from 1982 to 1994) and identified certain characteristics of this group that impact their e-learning preferences. Among these are that they expect more choices, prefer to have their options open for as long as possible, prefer to learn by doing, expect that services and features are customizable, expect services to be available instantly, and have poor tolerance for services that do not work reliably. Thus, the aim of our study was to 1) systematically assess the needs and attitudes of Griffith's dental students regarding a computer-based treatment planning tool; 2) identify the factors of importance for designing such a system as perceived by the students; and 3) identify elements of design that would increase the students' acceptance of such a tool and its functionality. Participants in the investigation were a cohort of fourth- and fifth-year dental students; it was carried out by means of a questionnaire and concurrent focus group discussions.

\section{Materials and Methods}

The process of developing CSTP software relies heavily on research and requires several stages of investigation and research. The first step is a userdriven investigation, addressing outcomes at the Reaction level, as classified by Kirkpatrick in 1996.
Kirkpatrick ${ }^{12}$ observed that research outcomes can be separated into four levels (Reaction, Learning, Behavior, Results), in which the first level addresses satisfaction, preferences, attitudes, and opinions. The outcomes of this study would indicate directions for further research at the higher levels, as development advances. Consequently, research at this stage must present clear research objectives, while allowing for unpredicted themes and factors to emerge that could identify further questions to be addressed at a higher level of investigation. In response to this need, we decided to use both qualitative and quantitative methodologies to meet the aims of the study.

To determine the perceived need among the student body for a computer-based, online CSTP software, a questionnaire was constructed to investigate students' perceived ability and willingness to use a computer-based aid for treatment planning and their overall likelihood of doing so. Students' approach to the use of such a tool was also investigated. A list of statements reflecting opinions and attitudes towards treatment planning was compiled by the project team after consultation with educators and students. Eighteen statements were selected; students would respond to each on a seven-point Likert scale with responses ranging from 1 (strongly disagree) to 7 (strongly agree). Expert opinion was sought from three senior academics in the field to establish that the statements had face validity and provided adequate coverage of the topic area. Ethical clearance was obtained from the Griffith University Research Ethics Committee. The one-page, anonymous questionnaire and the accompanying cover page were distributed during lectures towards the beginning of the first semester in 2008. Participants completed the survey in their own time and returned it via a drop box.

At the same time, focus groups were organized to discuss the use and role of a CSTP tool. A separate information and consent sheet was distributed to the entire classes of fourth-year $(n=44)$ and fifth-year $(n=45)$ dental students to recruit students into the focus groups. Entry into a lottery to win a voucher for dinner for two was offered as an added incentive to participate. The first ten respondents from each year level were selected. A simple flowchart of a hypothetical computer-based tool for treatment planning (Figure 1) was used as a basis for discussion. The flowchart was distributed to the students prior to the focus group discussion without any further instructions in order to minimize the risk of bias. We wanted to use the hypothetical CSTP to initiate discussion and not as a concrete proposal that the 


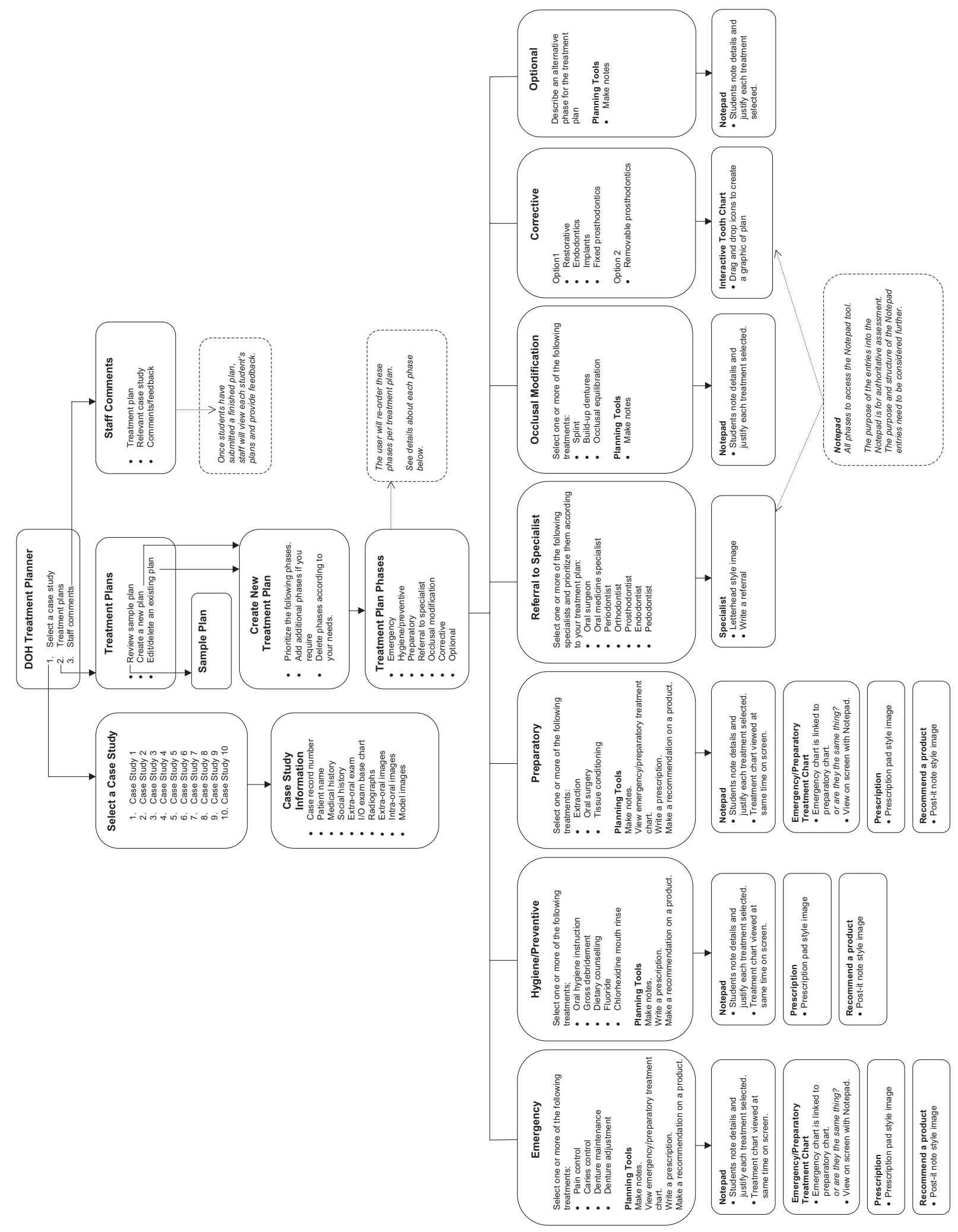

Figure 1. Flowchart of a hypothetical CSTP software presented as a basis for discussion in the focus groups 
students would directly approve or reject, so as to not exclude unpredicted factors or directions emerging in the discussion.

Two thirty-minute focus group discussions were held, one for each year level group. Participants were asked to protect their anonymity during the discussion by not using each other's names. The discussions were digitally recorded and later transcribed for further analysis. Two facilitators directed the discussions with structured questions on the following topics: the students' perception/understanding of the CSTP software; the potential of the software as a learning tool at the predoctoral level or for recent graduates; the potential of the software as an assessment tool at the predoctoral level or a self-assessment tool for recent graduates; the potential for CSTP software to improve students' current experience with treatment planning; possible risks or limitations in relation to the use of CSTP software; the potential for and limitations of an online environment for treatment planning; students' perceived usability of treatment planning software, their intention to use, and factors improving or limiting its applicability; and suggestions about the program structure, functions, and contents.

\section{Results}

\section{Survey Results}

Thirty-three fourth-year (75 percent of the class) and twenty fifth-year students (44 percent of the class) participated in the questionnaire part of the study during the 2008 summer semester. The total sample of fifty-three students contained 50 percent $(n=27)$ males. Means, standard deviations, and range of responses to each of the questionnaire items, by year level, are presented in Table 1. In the fifth-year student sample, there was some strong negative skew in the distribution of responses to items 4.1, 4.2, 4.3, 5.2, and 6.2. Inspection of histograms and raw data indicated that the negative skew was attributable to one student who responded in an extreme manner (i.e., strongly or moderately disagree) to every one of these items, perhaps due to nonavailability of access to remote computing. Based on the extreme nature and the pattern of this one respondent's responses, they were excluded from further analysis, after which

Table 1. Mean, standard deviation, and range of student responses to CSTP questionnaire items

\begin{tabular}{|c|c|c|c|c|c|c|c|}
\hline \multirow[b]{2}{*}{ Item } & & \multicolumn{3}{|c|}{ Fourth-Year Students } & \multicolumn{3}{|c|}{ Fifth-Year Students } \\
\hline & & Mean & $\mathrm{SD}$ & Range & Mean & SD & Range \\
\hline 1.1 & $\begin{array}{l}\text { I feel confident to tackle a complex, comprehensive } \\
\text { treatment plan. }\end{array}$ & 3.88 & 1.6 & $1-7$ & 4.85 & 1.6 & $1-7$ \\
\hline 1.2 & I feel intimidated ... & 3.97 & 1.6 & $1-6$ & 3.60 & 1.8 & $1-7$ \\
\hline 1.3 & I feel overwhelmed ... & 3.67 & 1.8 & $1-7$ & 3.45 & 1.9 & $1-7$ \\
\hline 1.4 & I feel underprepared ... & 4.45 & 1.7 & $1-7$ & 3.75 & 1.9 & $1-7$ \\
\hline 1.5 & I feel capable ... & 4.52 & 1.2 & $2-7$ & 5.05 & 1.5 & $2-7$ \\
\hline 1.6 & I feel well prepared ... & 3.85 & 1.3 & $2-7$ & 4.05 & 1.7 & $1-6$ \\
\hline 2.1 & $\begin{array}{l}\text { The present paper-based treatment planning system } \\
\text { helps me to formulate a comprehensive plan. }\end{array}$ & 4.00 & 1.5 & $2-6$ & 5.10 & 1.3 & $2-7$ \\
\hline 2.2 & $\ldots$ to prioritize a comprehensive plan. & 4.24 & 1.6 & $1-6$ & 4.65 & 1.5 & $2-7$ \\
\hline 3.1 & $\begin{array}{l}\text { I perceive the need for a computer-based tool that would } \\
\text { present a guided approach to comprehensive treatment } \\
\text { planning. }\end{array}$ & 6.18 & 0.9 & $4-7$ & 5.60 & 1.5 & $2-7$ \\
\hline 3.2 & ... present a structured approach. & 6.24 & 0.9 & $4-7$ & 5.75 & 1.3 & $3-7$ \\
\hline 4.1 & $\begin{array}{l}\text { If such a tool was available, I would be able to use } \\
\text { remote access to work on my plans and finish tasks or } \\
\text { assessments after hours (in my own time). }\end{array}$ & 6.67 & 0.6 & $5-7$ & 6.10 & 1.4 & $1-7$ \\
\hline 4.2 & ... willing to use remote access ... & 6.70 & 0.6 & $5-7$ & 6.15 & 1.4 & $1-7$ \\
\hline 4.3 & ... likely to use remote access ... & 6.61 & 0.6 & $5-7$ & 5.90 & 1.5 & $1-7$ \\
\hline 5.1 & $\begin{array}{l}\ldots \text { able to use it to plan cases other than my own clinical } \\
\text { cases in order to gain extra practice. }\end{array}$ & 6.39 & 0.7 & $5-7$ & 5.90 & 1.1 & $4-7$ \\
\hline 5.2 & $\ldots$ willing to use it to plan cases ... & 6.03 & 0.9 & $3-7$ & 5.60 & 1.5 & $1-7$ \\
\hline 5.3 & ... likely to use it to plan cases ... & 5.82 & 1.2 & $2-7$ & 5.45 & 1.5 & $1-7$ \\
\hline 6.1 & $\begin{array}{l}\text { I feel that such a tool would be an appropriate way for } \\
\text { the school to set treatment planning assignments. }\end{array}$ & 5.97 & 1.3 & $2-7$ & 5.90 & 1.1 & $4-7$ \\
\hline 6.2 & ... to assess my comprehensive treatment planning skills. & 5.70 & 1.3 & $2-7$ & 5.58 & 1.8 & $1-7$ \\
\hline
\end{tabular}


the distributions approached normality. No further transformations were conducted on the data set.

Survey items were combined to produce composite CSTP scores. Items concerning students' positive appraisals towards the task of comprehensive treatment planning $(1.1,1.5$, and 1.6) were added to form a composite Positive Self-Appraisal score, where higher scores represent a more positive appraisal. Items tapping negative appraisals (1.2, 1.3, and 1.4) were combined to form a Negative Self-Appraisal score, where higher scores represent a more negative appraisal. Items concerning the current paper-based treatment planning system (2.1 and 2.2) were combined to represent evaluation of the Current System, where a higher score represents a more positive evaluation. Items about the perceived level of need for a computer-based tool (3.1 and 3.2) were combined to form Perceived Need, where a higher score reflects a greater perceived need. Responses to items regarding use of remote access after hours (4.1, 4.2, and 4.3) were summed, forming an After Hours score, where higher scores represent a greater intention to utilize the proposed tool after hours. Similarly, three items on potential utilization of the tool for extra practice (5.1, 5.2, and 5.3) were combined into Extra Practice, where a higher score indicates a greater intention. Finally, items concerning perceived appropriateness of the CSTP tool as an assessment task (6.1 and 6.2) were combined to make one School Application score. Mean, SD, range, and internal reliability (Cronbach's $\alpha$ ) for each of these composite CSTP scores by year level are presented in Table 2.

The internal reliability measures for each composite score were high, indicating good consistency among items. The composite CSTP scores were normally distributed. There was strong overall agreement that there was a need for the proposed tool, and students generally agreed they would use it after hours and for extra practice. Very few scores fell in the low ends of the distributions, indicating that there were very few students in this cohort who disagreed with the need for and the likelihood of their use of the proposed tool.

Repeated measures t-tests were conducted to assess whether there were significant differences between positive and negative composite CSTP scores within each year-level. In both the fourth- and fifth-year groups, there was no statistically significant difference between average Positive and Negative Self-Appraisal scores, all $\mathrm{p}<0.05$. A series of independent groups t-tests were conducted to assess whether there were significant differences between the two year levels on any of the composite CSTP scores. A significant difference between year levels was found only for average Positive Self-Appraisal scores, $\mathrm{t}(50)=-2.03, \mathrm{p}=0.048$, such that fourth-year students had lower average Positive Self-Appraisals than fifth-year students. The year levels did not differ significantly on any of the other composite scores, all $p<0.05$. The nature and quality of differences between year levels would be better understood with the support of the qualitative data.

As a final check for differences between groups of students, a series of independent group t-tests were conducted as a check for gender differences on the measures. Interestingly, there were some significant differences between genders on the composite scores. The mean and standard deviations for males and females are presented in Table 3. There were significant differences between genders on two composite scores: males were on average higher in Positive Self-Appraisal scores than females $(\mathrm{p}=0.018)$; and males were significantly lower on Extra Practice scores than females $(\mathrm{p}=0.023)$.

Correlations among the composite CSTP scores are presented in Table 4. Among the fourthyear students, there was a moderate to strong negative

Table 2. Mean, SD, range, and internal reliability for students' composite CSTP scores

\begin{tabular}{lrrrrrrrrr} 
& \multicolumn{3}{c}{ Fourth-Year Students } & \multicolumn{3}{c}{ Fifth-Year Students } \\
\hline & Mean & SD & Range & $\alpha$ & Mean & SD & Range & $\alpha$ \\
\hline Positive Self-Appraisal & 12.24 & 3.6 & $6-21$ & .852 & 14.37 & 3.7 & $7-19$ & .765 \\
Negative Self-Appraisal & 12.09 & 4.3 & $3-20$ & .803 & 10.37 & 4.9 & $4-19$ & .879 \\
Current System & 8.24 & 2.8 & $3-12$ & .705 & 9.63 & 2.8 & $4-14$ & .879 \\
Perceived Need & 12.42 & 1.8 & $8-14$ & .901 & 11.32 & 2.9 & $5-14$ & .983 \\
After Hours & 19.97 & 1.6 & $15-21$ & .876 & 18.95 & 2.4 & $14-21$ & .942 \\
Extra Practice & 18.24 & 2.5 & $11-21$ & .857 & 17.53 & 2.9 & $12-21$ & .924 \\
School Application & 11.67 & 2.5 & $4-14$ & .899 & 11.42 & 2.7 & $6-14$ & .892 \\
\hline
\end{tabular}


linear relationship between Positive and Negative Self-Appraisals, such that higher positive scores were associated with lower negative scores and vice versa. Perceived need was moderately positively related to After Hours use and strongly positively related to School Application. These correlations indicate that fourth-year students who perceived a high degree of need for the proposed CSTP tool agreed that they would utilize it after hours in their own time to work on cases and complete tasks and also agreed that the CSTP tool would be a suitable way for the school to assess their work. Extra Practice was moderately related to School Application, indicating that these opinions were significantly and positively associated among the fourth-year students.

Among the fifth-year students, Positive and Negative Self-Appraisals were moderately negatively related. There were moderate positive linear relationships between Perceived Need and After Hours, Extra Practice, and School Application. As Perceived Need scores increased, scores on Extra Practice, After Hours, and School Application items also increased. After Hours and Extra Practice were moderately positively related, suggesting that fifthyear students felt they would be willing and able to make use of the tool outside of class time.

\section{Focus Group Discussions}

An independent researcher not otherwise involved in the study was given the transcript of the fourth- and fifth-year focus group discussions and asked to identify, categorize, and summarize the main issues that emerged from the students' responses during the discussions. Students' comments were organized under thematic units as directed by the themes targeted in the qualitative methodology, while new thematic units were developed for other issues that emerged.

Students' main perceptions of the program. The program was described by the students as an online treatment planning guide in which they could upload patient data and be directed to structuring the treatment plan in a standardized manner. The students expected that there would be an interface with a tutor at some point, providing them with feedback, evidence of what is correct or not, and maybe treatment options they missed. They perceived that the tool would allow them to feed in the data and details about the patient and that the software would then guide them through the process of planning and prepare the final layout for them. This process would save them time as they currently have to do

Table 3. Students' mean and standard deviation composite CSTP scores by gender

\begin{tabular}{|c|c|c|c|c|}
\hline & \multicolumn{2}{|c|}{ Male Students } & \multicolumn{2}{|c|}{ Female Students } \\
\hline & Mean & SD & Mean & SD \\
\hline Positive Self-Appraisal & 14.19 & 3.45 & 11.76 & 3.72 \\
\hline Negative Self-Appraisal & 10.40 & 4.53 & 12.56 & 4.40 \\
\hline Current System & 8.37 & 2.69 & 9.16 & 2.95 \\
\hline Perceived Need & 11.96 & 2.62 & 12.08 & 1.89 \\
\hline After Hours & 19.67 & 1.80 & 19.52 & 2.20 \\
\hline Extra Practice & 17.19 & 2.88 & 18.84 & 2.12 \\
\hline School Application & 11.59 & 2.31 & 11.56 & 2.87 \\
\hline
\end{tabular}

Table 4. Bivariate correlations among students' composite CSTP scores for each year level

\begin{tabular}{|c|c|c|c|c|c|c|c|}
\hline & 1 & 2 & 3 & 4 & 5 & 6 & 7 \\
\hline 1. Positive Self-Appraisal & - & $-.54 *$ & .22 & .18 & .28 & -.06 & .45 \\
\hline 2. Negative Self-Appraisal & $-.63 * *$ & - & .05 & -.33 & -.14 & .11 & -.24 \\
\hline 3. Current System & .19 & .01 & - & -.30 & -.21 & -.25 & .05 \\
\hline 4. Perceived Need & -.05 & -.06 & -.31 & - & $.65^{* *}$ & $.55^{*}$ & $.62 * *$ \\
\hline 5. After Hours & .11 & -.01 & .18 & $.35^{*}$ & - & $.53 *$ & .41 \\
\hline 6. Extra Practice & -.15 & .02 & .01 & .25 & .27 & - & .37 \\
\hline 7. School Application & .03 & -.05 & -.03 & $.73^{* *}$ & .11 & $.49 * *$ & - \\
\hline
\end{tabular}

Note: Fourth-year below the diagonal; fifth-year above the diagonal.

${ }^{*} \mathrm{p}<0.05,{ }^{* *} \mathrm{p}<0.01$ 
everything themselves, which they perceive as the hardest part of treatment planning.

Students also felt that it would be useful for treatment-planned cases to be part of a demonstration database that could be consulted by students and new graduates as a learning and training tool. In this capacity, they felt the software would be most valuable in the third year, when they are most unaware of the processes involved in treatment planning. The program would then be a good repository of previous treatment plans for them to study and compare with their current patients. In spite of these comments, it appeared that students in these discussions placed a higher priority on a need for software as functional guidance for treatment planning, related to their actual clinical patient cases, than on a need for software to be used as a training case study tool with hypothetical cases.

A treatment planning software as a learning tool. The students agreed that the software has potential as a training tool in treatment planning. They also agreed that whatever is saved in the database should be quality-assessed. Their perception is that the cases for training should be uploaded to the system once they have been finished and marked and that the cases should be organized into categories and subcategories of treatments (e.g., category: crowns and bridges; subcategory: crown in aesthetic zone). They felt the treatment planning program should give students a variety of cases they are not able to see in the clinic and that the faculty could guide them to cases of particular interest depending on the teaching needs.

A treatment planning software as a tool for assessment. The students were positive about the use of a case study tool as a means of assessment. In contrast to what they felt they have experienced in their education up to that point, students believed that a program with a standardized treatment planning format would make assessment fairer.

Potential for a computer-based treatment planning tool. The students believed that a standardized treatment planning tool would save them time in the clinic. They considered it important to be able to access the treatment plans from outside university premises. That would enable them to work on the treatment plan at their own pace and outside their allotted clinical time, which they felt was often not enough. They also saw a potential in allowing access to recent graduates, so they could browse through finalized and assessed cases while treating their first patients as qualified dentists. They quoted a similar structure to this with university libraries, which often allow twelve months of free library services after graduation.

Limitations of a computer-based treatment planning tool. Concerns were raised that a rigid program might result in missing treatment options for particular patients, and the students also perceived that the program might replace face-to-face time with professors and tutors. They expressed fears that online feedback might be time-consuming because sending questions and receiving answers would take more time than in face-to-face discussion with a tutor, which normally clarify everything in one instant. Some students also feared that a standardized program might limit opportunities to learn from different supervisors' experience because they will have to follow the same school treatment planning guidelines. They expressed an appreciation for the variety of different individuals' treatment opinions and find it useful to see the evidence each gives to support his or her decisions. The students also saw a danger that some would just copy and paste treatment plans from other cases without knowing why such a treatment was planned.

Comments on structure, functions, and content. The students suggested that the treatment plan should include various disciplines such as oral medicine, periodontology, pharmacology, and orthodontics. They also felt that financial aspects of the treatment plan, the patient's expectations about the treatment, and the patient's payment preferences should be included and that the software should enable students to generate a treatment cost quotation for the patient. The students expressed a preference for the program to enable the student to draw basic designs for partial dentures or upload photos and that it should be flexible enough to allow adding new, userdetermined options to the treatment plan, making allowance for unpredictable cases or situations. Finally, the students suggested including a drug database that alerts the user about possible drug interaction problems with the patient, e.g., a patient's allergy to a particular drug. They also expressed concerns about how the patient's privacy would be protected and suggested that all information should be deidentified.

\section{Discussion}

Both the questionnaire analysis and the outcome of the focus groups showed that the students have positive attitudes about a computer-based tool that will provide a guided and structured approach 
to treatment planning. They saw such software as having two important functions. First, it would be used as a training tool for the development of skills related to treatment planning. Second, it would be used as a guide in the treatment planning of students' own cases, directing them through the process with a standardized interface. It seems that the fourth-year students prioritized the second function, as they devoted much of their discussions to this aspect of the software. At the same time, they acknowledged that a training tool with hypothetical cases would be mostly beneficial in their third year of studies. The fact that both fourth- and fifth-year students appear generally positive about the need for and usability of a CSTP software might reflect their experiences with early clinical exposure in the Griffith University program to complex and multidisciplinary patient cases.

There was a clear suggestion that remote/afterhours access is an important issue, with students' returning strong affirmative responses to these survey items. There was a positive indication that students would be both willing and able to work remotely using a CSTP tool. Furthermore, the focus groups showed a strong preference for online access and access not restricted to university premises. Remote access raises confidentiality and security issues that will have to be properly addressed, yet it was clearly shown that access independent of time and place is a factor that appears to strongly affect the users' acceptance of the tool.

The students also seemed to focus on the transition to the workplace, as they believed that access to such a repository of cases as a recent graduate would be of great value at the beginning of their careers. CSTP software was perceived to be a useful tool for coaching about or becoming more comfortable using the Australian Dental Association list of dental services.

There has been a trend towards blended learning in higher education, ${ }^{2,14-16}$ partly because this style of education provides a maximum opportunity for students to organize and pace their own learning. A recent article by Bufano et al. ${ }^{17}$ analyzed the effect of using an online multimedia treatment planning tool on dental students' clinical data acquisition knowledge and skills. This training tool was designed to help improve students' actual and perceived knowledge about and self-assessed confidence in gathering and recording standardized data at a patient's initial visit. While that article focused on an aspect of the treatment planning process different from the one identified in our study, it is nevertheless an example of the successful introduction of an online multimedia training tool in a dental school.

Standardization versus flexibility was one of the most interesting themes that emerged from the discussions, without the students reaching a firm conclusion regarding the ideal balance between the two. Standardization was a positive aspect when it came to assessment, as students had experienced different tutors making assessments in different ways, making exams somehow unfair. At the same time, when the software was discussed as a learning tool, some concerns were raised that standardization might limit multiple and diverse input from different tutors, which was by some perceived as a disadvantage. Similarly, standardization was perceived as a good way to guide one through a treatment planning process in a short time, yet the students were also concerned that unless flexibility in adding userdetermined parameters is preserved, the software would not be applicable to many cases. These seemingly conflicting concerns might be attributed to the complexity of the topics but also to the fact that none of the students had any experience with using such a tool, so their feedback was based on their estimation of all the risks and benefits they could imagine. It is clear, however, that there is a critical balance to be achieved between standardization and flexibility and that this will be an important challenge for the design of a software tool. Based on these findings, increased standardization might be mostly welcome in the early curriculum (third-year students in this case), while as students advance, greater flexibility and user-driven parameters would be increasingly appreciated. The standardization-flexibility balance may also shift depending on the situation in which the tool is used since students perceive tutor diversity as a benefit in the learning process but see it as a major problem in assessment scenarios.

Human feedback appears to be greatly valued by the students, regardless of the structure of the software. Online feedback is expected at some stage although some concerns were raised that this would be time-consuming. It was clear that students would not like to see CSTP software as a replacement for tutor guidance and that some feared losing personal contact with teachers. Thus, at a certain point, tutor feedback, either online or in person, must be introduced into the process. The fact that both tutor and student could have access to the software irrespective of time and place could prove very important for accommodating this need. 


\section{Conclusions}

In light of our study's results, we conclude that it is desirable that a CSTP tool should be developed in such a way that it will allow online, after-hours access to a library of planned and unplanned patient cases. The software development should focus on two areas. One should provide a template for students to follow when diagnosing and planning treatment, and the other should provide a database of planned cases that will enhance the learning experience for students and extend the experience for new graduates. The template should encourage students new to the treatment planning process to approach a multifaceted case by identifying the treatment phases that are involved and then providing some options within the phases. However, the CSTP tool should have sufficient flexibility to allow more experienced students the option to propose additions and alterations to the basic list of possible phases and treatment options.

The tool should lead the student through the process of establishing and defining the phases of treatment and the dental specialties that will be involved in the comprehensive treatment of the patient. This will assist with the development of skills such as interdisciplinary communication with both dental specialists and professionals in the allied fields of oral hygiene therapy and dental technology. In addition, tutor feedback to students should be facilitated by the software. It is desirable that assessments and examinations of students' treatment planning skills in a structured way will be possible, helping to eliminate possible variations in grading that arise due to tutor subjectivity. Overall, it is envisaged that a CSTP tool will assist with the students' transition into the workplace upon graduation where it is common to find computer-based treatment planning, integrated with patient and practice management software.

\section{Acknowledgments}

The authors would like to acknowledge the contribution of Mr. Tim Park for his devoted assistance with the collection of the data and facilitation of the focus groups. We are also very thankful to Professor Newell Johnson, Griffith University, for his critical insight and input in this research. This project was funded by Griffith University Health Group through an educational grant.

\section{REFERENCES}

1. Rosenberg H, Grad HA, Matear DW. Effectiveness of computer-aided, self-instructional programs in dental education: a systematic review of the literature. J Dent Educ 2003;67(5):524-32.

2. Mattheos N, Stefanovic N, Apse P, Attström R, Buchanan $\mathrm{J}$, Brown P, et al. Potential of information technology in dental education. Eur J Dent Educ 2008;12:85-92.

3. Fouad AF, Burleson JA. Effectiveness of an endodontic diagnosis computer simulation program. J Dent Educ 1997;61(3):289-95.

4. Schittek-Janda M, Mattheos N, Nattestad A. Simulation of patient encounters using a virtual patient in periodontology instruction of dental students: design, usability, and learning effect in history-taking skills. Eur J Dent Educ 2004;8:111-9.

5. Crespo KE, Torres JE, Recio ME. Reasoning process characteristics in the diagnostic skills of beginner, competent, and expert dentists. J Dent Educ 2004;68(12):1235-44.

6. Garvey MT, O'Sullivan M, Blake M. Multidisciplinary case-based learning for undergraduate students. Eur J Dent Educ 2004;4:165-8.

7. Gupta B, White DA, Walmsley AD. The attitudes of undergraduate students and staff to the use of electronic learning. Br Dent J 2004;196:487-92.

8. Wenzel A, Gotfredson E. Students' attitudes towards and use of computer-assisted learning in radiology over a 10year period. Dentomaxillofac Radiol 1997;26:132-6.

9. Eynon R, Perryer G, Walmsley AD. Dental undergraduate expectations and opinions of web-based courseware to supplement traditional teaching methods. Eur J Dent Educ 2003; 7:103-10.

10. Steele DJ, Palensky JE, Lynch TG, Lacy NL, Duffy SW. Learning preferences, computer attitudes, and student evaluation of computerized instruction. Med Educ 2002;36:225-32.

11. McLoughlin C. The implication of research literature on learning style for the design of instructional materials. Aust J Educ Tech 1999;15:222-41.

12. Kirkpatrick D. Revisiting Kirkpatrick's four-level model. Training Development 1996;50:54-9.

13. Sweeney R. Millennial behaviors and higher education focus group results, 2009. At: http://library1.njit.edu/ staff-folders/sweeney/Millennials/Millennial-SummaryHandout.doc. Accessed: October 10, 2011.

14. Schittek M, Mattheos N, Lyon HC, Attström R. Computerassisted learning: a review. Eur J Dent Educ 2001;5:93100 .

15. Hillenburg KL, Cederberg RA, Gray SA. E-learning and the future of dental education: opinions of administrators and information technology experts. Eur J Dent Educ 2006;10:169-77.

16. Yip HK, Barnes IE. Information technology in dental education. Br Dent J 1999;189:327-32.

17. Bufano UBA, Branch-Mays G, Gilliam J, Romberg E. An online multimedia treatment planning tool: effect on dental students' knowledge in using standardized clinical data. J Dent Educ 2010;74(1):50-7. 